\title{
Titanium, Sinusitis, and the Yellow Nail Syndrome
}

\author{
Fredrik Berglund • Björn Carlmark
}

Received: 12 July 2010 / Accepted: 12 August 2010 /

Published online: 1 September 2010

C The Author(s) 2010. This article is published with open access at Springerlink.com

\begin{abstract}
Yellow nail syndrome is characterized by nail changes, respiratory disorders, and lymphedema. In a yellow nail patient with a skeletal titanium implant and with gold in her teeth, we found high levels of titanium in nail clippings. This study aims to examine the possible role of titanium in the genesis of the yellow nail syndrome. Nail clippings from patients with one or more features of the yellow nail syndrome were analyzed by energy dispersive X-ray fluorescence. Titanium was regularly found in finger nails in patients but not in control subjects. Visible nail changes were present in only half of the patients. Sinusitis with postnasal drip and cough was the most common complaint. The dominant source of titanium ions was titanium implants in the teeth or elsewhere. The titanium ions were released through the galvanic action of dental gold or amalgam or through the oxidative action of fluorides. In other patients the titanium was derived from titanium dioxide in drugs and confectionary. Stopping galvanic release of titanium ions or canceling exposure to titanium dioxide led to recovery. In one patient with a titanium implant, the symptoms recurred after renewed exposure to titanium. Yellow nail syndrome is caused by titanium
\end{abstract}

Keywords Titanium $\cdot$ Titanium dioxide $\cdot$ Sinusitis $\cdot$ Yellow nail syndrome $\cdot$ Reduction potentials

\section{Introduction}

Yellow nail syndrome was defined in 1964 as a combination of yellow and thickened nails, chronic respiratory disorders, and lymphedema [1]. The cause has previously not been clarified.

\footnotetext{
F. Berglund $(\bowtie)$

Solvägen 8 A, SE 19266 Sollentuna, Sweden

e-mail: fred.berglund@swipnet.se

F. Berglund $\cdot$ B. Carlmark

Scandlab, Sollentuna, Sweden

B. Carlmark

e-mail: bearco@telia.com
} 
Our contribution derives from our interest in metal toxicology. In 1997 we saw a patient with a diagnosed yellow nail syndrome. She had a metal implant in knee and gold in many of her teeth. Analysis for metals in nail clippings revealed high levels of titanium [2]. Since then we have encountered more than 30 patients with one or more features of the syndrome.

\section{Patients and Methods}

Most patients consulted us after contact with the Swedish Society of Dental Amalgam Patients. The patients were interviewed concerning symptoms and exposure to metals (amalgam, gold, titanium). The majority had titanium implants as well as dental gold inlays or crowns. In other patients the titanium was derived from titanium dioxide in medicines or confectionary.

Nail clippings or small fragments of shed nails were analyzed by energy dispersive X-ray fluorescence, with a detection limit of $1{\mu \mathrm{gg}^{-1}}^{-1}$, referred to the surface of the sample [3].

\section{Results}

Titanium levels in nails varied between 1.1 and $170 \mu \mathrm{gg}^{-1}$, with a median level of $5 \mu \mathrm{gg}^{-1}$ (Tables 1 and 2). Shed nails had high levels (48, 41, and $\left.22 \mu \mathrm{gg}^{-1}\right)$, but a few nail clippings

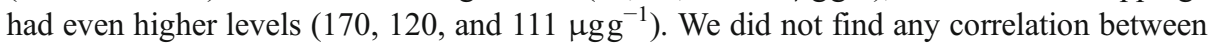
titanium levels and yellowness or thickness of nails. Titanium was never found in nails from control subjects.

Recently, we examined separate nails of the left hand in two patients. The thumb nail had higher level (5.6 and $4.1{\mu g g^{-1}}^{-1}$ than the other four nails $\left(2.8-3.2\right.$ and 3.1-4.1 $\mathrm{\mu gg}^{-1}$, respectively). In two patients the levels in nails from thumb and big toe were identical $\left(1.7 \mu \mathrm{gg}^{-1}\right)$ or nearly identical $\left(1.7\right.$ versus $\left.1.6 \mu \mathrm{gg}^{-1}\right)$. In one patient the titanium level in a shed nail was $48 \mathrm{\mu gg}^{-1}$, but in fresh clippings $6.7 \mathrm{\mu gg}^{-1}$. At present we ask for clippings from the left thumb nail, except when shed nails are available.

\section{Titanium Implant Patients}

Patients with titanium implants are listed in Table 1: 23 female and 3 males, aged 1586 years at onset of symptoms. They had titanium implants in the teeth or jaws (20 patients), in the legs (four patients), or in the abdomen (one patient). In one patient the only source of titanium was her spectacles with titanium frames.

The cathode in the galvanic system consisted of gold in or on the teeth (20 patients), in a gold ring (two patients), or of dental amalgam (two patients). In three patients the local application of fluorides seems to have released titanium ions from dental titanium constructions.

A few case reports will illustrate some important points.

Patient 1 got a titanium implant in her right knee. Half a year later, she developed viscous postnasal drip and a productive cough. Later, her nails became yellow and thickened. She shed the nails on both thumbs and on her right middle finger. She had gold in many of her teeth. Analysis of nail clippings revealed high titanium levels $\left(120 \mathrm{\mu gg}^{-1}\right)$. Three years later she had normal nails and no cough, but her knee implant had loosened. She received a new titanium implant, and a year later she again had a productive cough and yellow nails with titanium $\left(1.1 \mathrm{\mu gg}^{-1}\right)$. 
Table 1 Titanium implant patients

\begin{tabular}{|c|c|c|c|c|c|c|c|}
\hline $\begin{array}{l}\text { Patient } \\
\text { no. }\end{array}$ & Sex & Exposure & $\begin{array}{l}\text { Nail Ti } \\
\left(\mu g^{-1}\right)\end{array}$ & $\begin{array}{l}\text { Yellow } \\
\text { nails }\end{array}$ & Sinusitis & $\begin{array}{l}\text { Pleural } \\
\text { effusion }\end{array}$ & Lymphedema \\
\hline 1 & $\mathrm{~F}$ & Ti in knee, gold in teeth & 120 & + & + & & \\
\hline 2 & $\mathrm{~F}$ & $-"-$ & 3 & + & & & \\
\hline 3 & M & $\mathrm{Ti}$ in knees, gold in teeth & 7 & + & & & \\
\hline 4 & M & Ti in femur, amalgam in teeth & 48 & + & & + & + \\
\hline 5 & $\mathrm{~F}$ & Ti clips in guts, gold in teeth & 20 & & + & & \\
\hline 6 & $\mathrm{~F}$ & Ti pin + gold crown in tooth & 41 & + & + & & \\
\hline 7 & $\mathrm{~F}$ & $-"-$ & 4 & + & + & & \\
\hline 8 & $\mathrm{~F}$ & $-"$ & 15 & + & + & & \\
\hline 9 & M & $-"-$ & - & $?$ & ++ & & \\
\hline 10 & $\mathrm{~F}$ & Ti pin in tooth, gold ring & 6 & & + & & \\
\hline 11 & $\mathrm{~F}$ & Ti fixtures + gold & 3 & & + & & \\
\hline 12 & $\mathrm{~F}$ & $-"$ & 32 & & + & & \\
\hline 13 & $\mathrm{~F}$ & $-"$ & 111 & & & & + \\
\hline 14 & $\mathrm{~F}$ & $-"$ & 3 & & + & & \\
\hline 15 & $\mathrm{~F}$ & $-"$ & 170 & + & + & & \\
\hline 16 & $\mathrm{~F}$ & -”- & 1.6 & + & & & \\
\hline 17 & $\mathrm{~F}$ & -”- & 1.1 & & + & & \\
\hline 18 & $\mathrm{~F}$ & $-"$ & 7 & + & + & & + \\
\hline 19 & $\mathrm{~F}$ & $-"-$ & 20 & $?$ & + & & $(+)$ \\
\hline 20 & $\mathrm{~F}$ & $\mathrm{Ti}$ bridge + gold screws & 4 & & + & & \\
\hline 21 & $\mathrm{~F}$ & $-"-$ & 35 & + & & & \\
\hline 22 & $\mathrm{~F}$ & Ti crown + amalgam & 13 & & + & & \\
\hline 23 & $\mathrm{~F}$ & Ti bridge + fluoride & 1.8 & & + & & \\
\hline 24 & $\mathrm{~F}$ & $\mathrm{Ti}$ in teeth + fluoride & 1.5 & & + & & \\
\hline 25 & $\mathrm{~F}$ & $-"-$ & 4 & & + & & \\
\hline 26 & $\mathrm{~F}$ & Ti in specs, gold in teeth & 2.3 & + & + & & \\
\hline
\end{tabular}

Ti titanium, $M$ male, $F$ female

Table 2 Titanium dioxide patients

\begin{tabular}{|c|c|c|c|c|c|c|}
\hline $\begin{array}{l}\text { Patient } \\
\text { number }\end{array}$ & Sex & Exposure to titanium dioxide & Nail Ti $\left(\mu g^{-1}\right)$ & $\begin{array}{l}\text { Yellow } \\
\text { nails }\end{array}$ & Sinusitis & Lymphedema \\
\hline 1 & $\mathrm{~F}$ & Diclofenac & 22 & + & & \\
\hline 2 & M & 7 drugs + gum & 2.5 & + & + & \\
\hline 3 & M & Chewing gum & 43 & + & & \\
\hline 4 & M & Celecoxib & & + & + & \\
\hline 5 & $\mathrm{~F}$ & Confectionary & 2 & $?$ & & + \\
\hline 6 & $\mathrm{~F}$ & Zopiklon & 3 & & + & \\
\hline 7 & $\mathrm{~F}$ & 13 drugs + licorice & 2 & & + & \\
\hline 8 & M & 4 drugs & 2 & & + & + \\
\hline
\end{tabular}

Ti titanium, $M$ male, $F$ female 
Patient 5 had about 50 titanium staples and five titanium clips in her sigmoid intestine after laparoscopic surgery. She had gold inlays and crowns in 13 teeth. Intense abdominal itching and burning pain and a "strange cough" developed within a few weeks. Her nails looked normal but had a titanium level of $20 \mathrm{\mu gg}^{-1}$. After 15 months the staples and three clips were surgically removed, but two clips remained, as did her symptoms. Seven months later all gold had been removed from her teeth, and nail titanium soon dropped to $6.6 \mu \mathrm{g}$ $\mathrm{g}^{-1}$; after another year and a half, she was free of symptoms.

Patient 9 had two dental root canal titanium posts and three gold crowns. He wrote that "the formation of mucus in sinuses and bronchi is enormous." He died in 1993, before we knew anything about yellow nail syndrome.

Patient 10 had titanium in one tooth. She had recurrent sinusitis and had to remove a gold ring because of swelling and cyanosis of her ring finger.

Patient 15 had titanium fixtures in her jaws. Dentures were fastened with gold screws. Her nails turned yellow but became normal when the gold screws were removed. Yellow nails recurred a year later, probably due to the combination of wearing a gold ring and perspiration during a hot weather spell.

Patient 26 had amalgam fillings replaced with gold in eight teeth. She wore spectacles with titanium frames. After 15 months with titanium frames, her nail lunulae waned. Later, her nails turned yellowish brown; two nails were shed. In the subsequent 5 years, after abandoning her titanium frames, her nails slowly turned normal.

Symptoms disappeared over a period of several months in four patients (patients 3, 5, 8, and 15) when gold in their teeth was removed.

\section{Titanium Dioxide Patients}

Four males and four females had symptoms of yellow nail syndrome after exposure to titanium dioxide in drug tablets or confectionary (Table 2). They were 15-79 years old at onset of symptoms. Patient 4 had been using celecoxib but stopped before we saw him, and he had thrown away his shed nails. Two patients had yellow nails, but no other symptoms: patient 1 consuming diclofenac and patient 3 using chewing gum. Patient 5 had lymphedema in her legs since age 15-massive consumption of confectionary was evidently the source of her titanium dioxide. Remaining patients consumed one or more drugs containing titanium dioxide.

\section{Discussion}

Symptoms of the Yellow Nail Syndrome

The term "yellow nail syndrome" was coined in 1964 by Samman and White [1]:

The main features of the syndrome are slow growing discoloured nails and oedema....

The colour is usually pale yellow but it may be slightly greenish.

Other features are recurrent pleural effusions, intermittent cough with sputum, and bronchiectasis $[4,5]$.

Several authors report sinusitis, some mentioning radiography revealing mucoid thickening of one or more sinuses [6-10]. Varney et al. [9] — at a Nose Clinic in London — reported that 14 out of 17 patients with yellow nail syndrome suffered severe rhinosinusitis, which predated nail changes in four, coincided with yellow nails in six, and occurred later in the 
remaining seven patients. Troublesome daily postnasal drip was reported by 13 patients. Sinus radiographs showed mucosal thickening, with fluid levels occasionally reported.

Similarly, in our material, sinusitis was the most common symptom in 25 out of 36 patients. Several patients spontaneously mentioned postnasal drip and a "strange cough" as a main feature.

Pathogenesis of Edema and Effusions in Yellow Nail Syndrome

Emerson found that pleural effusion occurred in patients with chronic lymphedema and noted its high protein content (40,50, and $90 \mathrm{gL}^{-1}$ in three patients) [4]. It always re-accumulated after drainage. He suggested that increased capillary permeability was an important factor in yellow nail syndrome.

\section{Pathogenesis of the Yellow Nails}

Samman and White [1] assumed that defective lymph drainage and the nail changes were related. This relationship was questioned by two doctors in Nigeria in 1978: "If lymphatic abnormality is concerned in the pathogenesis of the ungual condition, then patients with chronic elephantiasis (as in filariasis or post-mastectomy states) haemolymphangioma might be expected to occasionally manifest the yellow nail phenomenon". They suggested that "chemical analysis of the pathological yellow nails may help to elucidate the aetiology of this syndrome" [11]. Our finding of titanium in the nails of yellow nail patients seems, indeed, to have solved the problem of the etiology.

Galvanic or Oxidative Release of Titanium Ions from Titanium Implants

Our body shows high electrical conductivity. This enables our recording of the electrocardiogram through electrodes applied to the skin. The conductivity of the skin is enhanced by perspiration (hypotonic saline). Ions of different sorts can be introduced from the skin surface into the body by means of electric current, so-called iontophoresis.

Metals with different reduction potentials [12] (Table 3) may give rise to galvanic phenomena within the body or across the skin. A young man with a golden ear ring told us that holding a Coca-Cola can for a while in his hand gave rise to a buzzing sensation in the ear. The dominant cause of yellow nails in our patients was the galvanic interaction between gold in the teeth and titanium implants. A surface layer of titanium oxide on the implant forms spontaneously in air, but this is also sensitive to galvanic corrosion

Table 3 Reduction potentials

\begin{tabular}{lc}
\hline Reaction & Potential (V) \\
\hline $\mathrm{Ti}^{+2}+2 \mathrm{e}^{-} \Leftrightarrow \mathrm{Ti}$ & -1.63 \\
$\mathrm{TiO}_{2}+4 \mathrm{H}^{+}+4 \mathrm{e}^{-} \Leftrightarrow \mathrm{Ti}+2 \mathrm{H}_{2} \mathrm{O}$ & -0.86 \\
$\mathrm{Ag}^{+}+\mathrm{e}^{-} \Leftrightarrow \mathrm{Ag}$ & +0.80 \\
$\mathrm{Hg}^{+2}+2 \mathrm{e}^{-} \Leftrightarrow \mathrm{Hg}$ & +0.85 \\
$\mathrm{Au}^{+}+\mathrm{e}^{-} \Leftrightarrow \mathrm{Au}$ & +1.69 \\
$\mathrm{~F}_{2}+2 \mathrm{e}^{-} \Leftrightarrow 2 \mathrm{~F}^{-}$ & +2.87 \\
\hline
\end{tabular}


(cf. Table 3). In one patient iontophoresis of titanium ions from titanium spectacles to dental gold occurred.

After removal of gold, four of our patients became free of symptoms after several months. This, together with the persistence of symptoms in patient 26 , indicates that removal of gold is more important than removal of the titanium. Some of the female patients reported intolerance to gold jewelry. One patient (patient 8) reacted strongly to gold in epicutaneous testing after receiving titanium implants (most likely a nonspecific reaction). Two female patients (patients 10 and 21) reported intolerance to gold jewelry - we regularly advise our amalgam and titanium patients to remove all metal jewelry.

Three patients with dental titanium constructions had been exposed to fluoride gels or solutions (cf. Table 3). In vitro, the oxidative release of titanium ions increases sharply in the presence of fluoride [13-15].

\section{Titanium Dioxide as a Source of Titanium in Nails}

Titanium dioxide, $\mathrm{TiO}_{2}$, is insoluble in water and acid but soluble in alkali. It is the most widely used white pigment because of its brightness and high refractive index. It was in use in medicines even before 1934, when registration of drugs was made compulsory in Sweden. It was approved as a color additive (maximum $4 \mathrm{~g} \mathrm{~kg}^{-1}$ ) in confectionary in Sweden in 1958. Titanium dioxide is also widely used in tooth pastes, cosmetics, and sun protection remedies.

Several publications mention the exposure to drugs (actually contain titanium dioxide) preceding the development of yellow nails and also return to normal conditions months after withdrawal of the drugs [16-18]. We have similar experiences, but some of our patients have difficulties finding titanium-free drug replacements.

We suspect that heavy loads of amalgam increase intestinal permeability. Seven of our eight titanium dioxide patients had more than ten sizable amalgam fillings and had gastrointestinal manifestations, mostly diarrhea. In patient 3 the titanium evidently derived from chewing gum only, suggesting absorption through the oral mucosa.

\section{Conclusion}

Yellow nail syndrome almost always involves upper and lower airways, giving rise to sinusitis and cough. It is caused by the galvanic release of titanium ions by other metals or by the oxidative release of titanium ions by fluorides or by the uptake of titanium dioxide from the digestive tract. Presence of titanium in the nails confirms the diagnosis, even in the absence of characteristic nail changes.

Acknowledgment Analytical costs were defrayed by the Swedish Society of Dental Amalgam Patients, Trollhättan, Sweden.

Fredrik Berglund has been responsible for patient contacts.

Björn Carlmark has been responsible for chemical analyses.

\section{Conflict of Interest None.}

Open Access This article is distributed under the terms of the Creative Commons Attribution Noncommercial License which permits any noncommercial use, distribution, and reproduction in any medium, provided the original author(s) and source are credited. 


\section{References}

1. Samman PD, White WF (1964) The "yellow nail" syndrome. Br J Dermatol 76:153-157

2. Berglund F, Carlmark B (1999) Yellow nail syndrome in patients with titanium and gold implants [Abstract]. Toxicol Lett 109(suppl 1):53

3. Forsell M, Marcusson JA, Carlmark B et al (1997) Analysis of the metal content of in vivo fixed dental alloys by means of a simple office procedure. Swed Dent J 21:161-168

4. Emerson PA (1966) Yellow nails, lymphoedema, and pleural effusions. Thorax 21:247-253

5. Zerfas AJ (1966) Yellow nail syndrome with bilateral bronchiectasis. Proc Royal Soc Med 59:448, for HJ Wallace

6. Nakielna EM, Wilson J, Ballon HS (1976) Yellow nail syndrome: report of three cases. Can Med Assoc J $115: 46-48$

7. Hassard AD, Martin J, Ross JB (1984) Yellow nail syndrome and chronic sinusitis. J Otolaryngol 13:318-320

8. Camilleri AE (1990) Chronic sinusitis and the yellow nail syndrome. J Laryngol Otol 104:811-813

9. Varney VA, Cumberworth V, Sudderick R et al (1994) Rhinitis, sinusitis and the yellow nail syndrome: a review of symptoms and response to treatment in 17 patients. Clin Otolaryngol Allied Sci 19:237-240

10. Cebeci F, Celebi M, Onsun N (2009) Nonclassical yellow nail syndrome in six-year-old girl: a case report. Case J 2:165-169

11. Somorin AO, Adesugba AJ (1978) The yellow nail syndrome associated with sinusitis, bronchiectasis and transitory lymphoedema in a Nigerian patient. Clin Exp Dermatol 3:31-33

12. Hunsberger JF (1976) Electrochemical series Table I. In: Weast RC (ed) Handbook of chemistry and physics, 57th edn. CRC Press, Boca Raton, pp D141-D143

13. Reclaru L, Meyer J-M (1998) Effects of fluoride on titanium and other dental alloys in dentistry. Biomaterials 19:85-92

14. Strietzel R, Hösch A, Kalbfleisch H et al (1998) In vitro corrosion of titanium. Biomaterials 19:14951499

15. Schiff N, Grosgogeat B, Lissac M et al (2002) Influence of fluoride content and $\mathrm{pH}$ on the corrosion resistance of titanium and its alloys. Biomaterials 23:1995-2002

16. Ben-Yehuda A, Ben-Chetrit E, Eliakim M (1986) Yellow nail syndrome: case report and review of the literature. Isr J Med Sci 22:117-119

17. Ishizaki C, Sueki H, Kohsokabe S, Nishida H (1995) Yellow nail induced by bucillamine. Int J Dermatol 34:493-494

18. David-Vaudey E, Jamard B, Hermant C et al (2004) Yellow nail syndrome in rheumatoid arthritis: a drug-induced disease? Clin Rheumatol 23:376-378 